\title{
Surveillance of avian influenza viruses in Papua New Guinean poultry, June 2011 to April 2012
}

\author{
Marinjho Jonduo, a Sook-San Wong, ${ }^{b}$ Nime Kapo, ${ }^{c}$ Paskalis Ominipi, ${ }^{c}$ Mohammad Abdad, a Peter Siba, ${ }^{\text {a Pamela }}$ \\ McKenzie, ${ }^{b}$ Richard Webby and Paul Horwooda \\ Correspondence to Paul Horwood (paul.horwood@pngimr.org.pg).
}

We investigated the circulation of avian influenza viruses in poultry populations throughout Papua New Guinea to assess the risk to the poultry industry and human health. Oropharyngeal swabs, cloacal swabs and serum were collected from 537 poultry from 14 provinces of Papua New Guinea over an 11-month period (June 2011 through April 2012). Virological and serological investigations were undertaken to determine the prevalence of avian influenza viruses. Neither influenza $A$ viruses nor antibodies were detected in any of the samples. This study demonstrated that avian influenza viruses were not circulating at detectable levels in poultry populations in Papua New Guinea during the sampling period. However, avian influenza remains a significant risk to Papua New Guinea due to the close proximity of countries having previously reported highly pathogenic avian influenza viruses and the low biosecurity precautions associated with the rearing of most poultry populations in the country.

l

nfluenza virus is a major respiratory pathogen that infects an average of $5-15 \%$ of the global population each year, with approximately 500000 human deaths related to influenza annually. ${ }^{1}$ Currently all known influenza $A$ viruses are naturally maintained in aquatic birds. $^{2}$ Occasionally these influenza viruses of avian lineage cross natural species barriers and infect other susceptible bird species and/or mammals including humans, pigs and horses. The interspecies transmission of highly pathogenic avian influenza (HPAI) virus to poultry populations often results in devastating disease outbreaks.

In 1996, a HPAl strain of H5N1 emerged in South-East Asia and extended throughout several Asian, Middle Eastern, African and European countries. Its reemergence in 2003 resulted in the death of more than 62 million birds in Thailand alone, almost half of which were backyard poultry. ${ }^{3}$ Death caused by infection and preventive measures (such as depopulation) implemented to control the spread of the HPAI H5N1 virus resulted in considerable socioeconomic burdens for many of the affected countries. ${ }^{4}$ The recent emergence of a novel H7N9 virus in China (March 2013) has increased fears about the spread of influenza viruses with pandemic potential from poultry populations. ${ }^{5}$ The transmission of these viruses over long distances by migrating birds is a concern for countries such as Papua New Guinea that have large poultry populations with few biosecurity precautions.

Poultry production accounts for $45 \%$ of the total annual livestock production in Papua New Guinea, and poultry consumption is second only to pigs. ${ }^{6}$ The short turn-around time, ease in rearing, market demand and high income from poultry production makes it more profitable than most other livestock rearing in Papua New Guinea. Most poultry farming in the country is conducted in semi-enclosed areas or free-ranged village settings. Relatively few poultry farms are commercialized and therefore do not have high biosecurity settings to reduce potential introduction of influenza viruses into the poultry population. The freeranged village/backyard chickens are often raised together with other animals within the same pen (e.g. pigs and ducks). The village chickens also have unrestricted access to water and feed sources that may be utilized by wild birds, thus increasing the risk of exotic disease transmission.

In this paper we report a cross-sectional study to determine the presence of circulating avian influenza

\footnotetext{
Papua New Guinea Institute of Medical Research, Goroka, Papua New Guinea.

b Center of Excellence for Influenza Research and Surveillance, St Jude Children's Research Hospital, Memphis, United States of America.

Papua New Guinea National Agriculture Quarantine and Inspection Authority, Port Moresby, Papua New Guinea Submitted: 21 October 2013; Published: 19 December 2013

doi: 10.5365/wpsar.2013.4.4.004
} 
Table 1. Summary of the poultry* sampling sites in Papua New Guinea

\begin{tabular}{lccccc}
\hline \multicolumn{1}{c}{ Sampling site (Town, Province) } & $\begin{array}{c}\text { Number of } \\
\text { sub-sites }\end{array}$ & Low & Medium & High & Total \\
\hline Daru, Western Province & 18 & $69(13)$ & 0 & 43 & $112(13)$ \\
Goroka, Eastern Highlands Province & 5 & 25 & $28(9)$ & 0 & $53(9)$ \\
Mt Hagen, Western Highlands & 6 & $15(3)$ & $20(2)$ & 24 & $59(5)$ \\
Province & & & 6 & 0 & 6 \\
Mendi, Southern Highlands Province & 2 & 0 & $36(8)$ & 25 & $88(12)$ \\
Lae, Morobe Province & 4 & $27(4)$ & 8 & 0 & 28 \\
Kavieng, New Ireland Province & 7 & 20 & $14(5)$ & 0 & $22(5)$ \\
Port Moresby, Central Province & 4 & 8 & $22(9)$ & 0 & $22(9)$ \\
Madang, Madang Province & 1 & 0 & $10(2)$ & 0 & $20(2)$ \\
Rabaul, East New Britain Province & 6 & 10 & 5 & 2 & 32 \\
Kimbe, West New Britain Province & 8 & 25 & 20 & 0 & $40(7)$ \\
Vanimo, West Sepik Province & 1 & $20(7)$ & 2 & 0 & 4 \\
Kundiawa, Simbu Province & 1 & $6(2)$ & 12 & 0 & $18(2)$ \\
Wabag, Enga Province & 8 & 15 & $\mathbf{1 7}(6)$ & 0 & $32(6)$ \\
Alotau, Milne Bay Province & 11 & $\mathbf{2 4 2 ( 2 9 )}$ & $\mathbf{2 0 0 ( 4 1 )}$ & 94 & $\mathbf{5 3 6 ( 7 0 )}$ \\
\hline TOTAL & $\mathbf{8 2}$ & & & 0 \\
\hline
\end{tabular}

* Samples in brackets were from ducks (unknown species) with the remaining from chickens.

viruses and the seroprevalence of neutralizing antibodies to avian influenza viruses in poultry populations across Papua New Guinea.

\section{MATERIALS AND METHODS}

Oropharyngeal swabs, cloacal swabs and serum were obtained from 536 poultry (466 chickens and 70 ducks) from 82 sub-sites within 14 selected provinces from June 2011 to April 2012 (Table 1 and Figure 1). Qualified field officers from the Papua New Guinea National Agriculture Quarantine and Inspection Authority carried out the sampling during their routine surveillance programme, adhering to the guidelines of the Food and Agriculture Organization of the United Nations (FAO) for avian sampling. ${ }^{7}$

Sampling was conducted in three types of biosecurity settings: high, medium and low. These classifications were based on the amount of exposure the sampled poultry population had to other birds and/or animals. Thus, poultry sites with little-to-no exposure to other animals or birds were classified as high (e.g. commercial farms); sites with some exposure were classified as medium (e.g. semi-enclosed farms); and sites with unlimited exposure were classified as low biosecurity containment (e.g. free-range village chickens).
Oropharyngeal swabs, cloacal swabs and serum were obtained from poultry and sent at $4{ }^{\circ} \mathrm{C}$ to the laboratory for analysis. Upon arrival at the laboratory, the samples were stored at $-80{ }^{\circ} \mathrm{C}\left(-20{ }^{\circ} \mathrm{C}\right.$ for sera) until required for analysis. Total RNA was extracted from oropharyngeal and cloacal swabs using the QIAamp Viral RNA Minikit (Qiagen, Hilden, Germany), according to the manufacturer's instructions. The extracted RNA was tested for the presence of influenza A virus by real time reverse-transcriptase polymerase chain reaction (PCR) assays supplied by the Centers for Disease Control and Prevention (Atlanta, GA, USA). Samples positive or equivocal for avian influenza viruses were further tested for influenza $\mathrm{A} / \mathrm{H} 5$ and $\mathrm{A} / \mathrm{H} 7$ using previously published assays. ${ }^{8}$ Aliquots of all samples were sent to the Center of Excellence for Influenza Research and Surveillance, St Jude Children's Research Hospital (Memphis, TN, USA) for isolation and subtyping of avian influenza virus isolates.

A total of 36 paired oropharyngeal and cloacal samples collected from farms and provinces that had samples deemed equivocal were passaged three times in 10-day old embryonated chicken eggs. A sample was considered negative for isolation if no virus was isolated upon three passages. For increased sensitivity in detection of viral genome, deep-sequencing was also 
Figure 1. Map of Papua New Guinea showing the 14 provinces where sampling was conducted

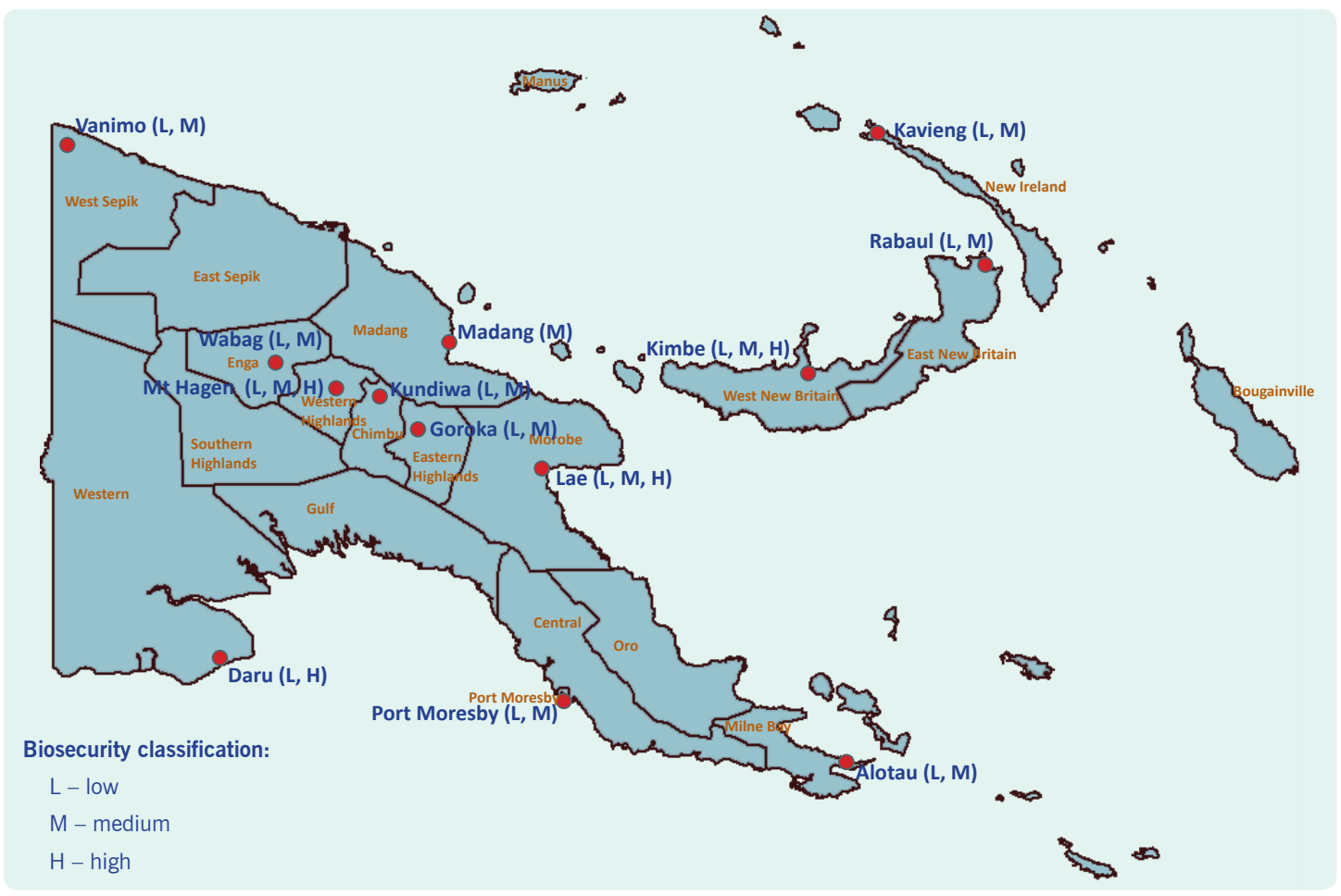

performed on the equivocal samples. Briefly, viral RNA was extracted, transcribed to cDNA and subjected to whole-genome amplification according to previously published methods. ${ }^{9}$ The resulting PCR products were then library-prepped and sequenced on the Illumina MiSeq platform (Illumina, San Diego, CA, USA) using the paired-end sequencing chemistry. After removal of MiSeq indices, analysis was performed using CLC Genomics Workbench 6.5 (CLC bio, Aarhus, Denmark) using the following process: for quality trimming sequence reads were filtered at the quality-limit threshold of 0.05 ; short reads and reads with more than two ambiguous bases were removed. Remaining reads were then de novo assembled using the fast-contig mapping mode at the minimum contig length of 200 base pairs; pairedreads were aligned using the scaffold option. Assembled contigs were then subjected to BLASTn search against the National Center for Biotechnology Information (Bethesda, MD, USA) database for viral sequences.

Sera were analysed for the presence of influenza A virus antibodies using the IDEXX AI MulitS Screen ELISA (IDEXX Laboratories, Rydalmere, Australia), according to the manufacturer's instructions. All serum samples were individually tested on three separate occasions to ensure the validity of results.

\section{RESULTS}

Influenza A virus was not detected in any of the oropharyngeal or cloacal swabs ( $n=536$ each). Four samples had results recorded as equivocal as crossingthreshold values of 36-40 were detected. These samples were tested for influenza $\mathrm{A} / \mathrm{H} 5$ and $\mathrm{A} / \mathrm{H} 7$ using real-time PCR; however, all of the samples were negative. Further analysis of these samples using egg inoculation and nextgeneration sequencing at St Jude Children's Research Hospital (Memphis, TN, USA) resulted in no detection of influenza A virus.

Despite all serum samples being tested on three independent occasions, influenza $A$ antibodies were not detected in any of the samples. Positive and negative control reactions supplied with the kits confirmed the validity of the results.

\section{DISCUSSION}

This paper is the first to investigate the presence and distribution of avian influenza viruses in poultry populations in Papua New Guinea. Influenza virus and antibodies were not detected in any of the samples, suggesting that there is low (or no) circulation of avian 
influenza viruses in poultry in the country. Poultry and wild bird surveillance programmes in other countries, such as Australia and New Zealand, have also found low prevalence of circulating avian influenza viruses. ${ }^{10}$

The failure to detect avian influenza viruses in poultry does not necessarily mean that Papua New Guinea is at low risk for an outbreak. The recent detection of H5N1 in West Papua (Indonesia) ${ }^{11}$ is a concern for Papua New Guinea as this region shares a land border with West Papua.The recent outbreak of Newcastle Disease virus in poultry populations in the north-west region of Papua New Guinea ${ }^{12}$ highlights the potential for the incursion of exotic diseases into this region. Indeed the maiden outbreak of chikungunya was first detected in this region ${ }^{13}$ before subsequently spreading throughout much of the country.

Papua New Guinea is in close proximity to South-East Asian countries endemic for the H5N1 and H7N9 viruses. 3,5 The spread of these viruses through the migration of waterfowl may be a potential source of incursion into non-endemic areas. ${ }^{14}$ Although wild bird surveillance studies have shown that there is a low prevalence of avian influenza viruses in Australia, and an absence of HPAI, ${ }^{10}$ avian influenza introduction from this direction is also a possibility given the nomadic migration of some duck species between Australia and Papua New Guinea. ${ }^{15}$ H5N1 has not been reported in the Pacific region since its re-emergence in 2003, despite being detected in the West Papua province of Indonesia. Previous studies have suggested that the Pacific region is protected from the incursion of HPAI influenza viruses by the uncommon migration of waterfowl across Wallace's Line. ${ }^{16}$ However, it is important that active surveillance continues so that outbreak mitigation steps can be rapidly implemented in the event of incursion of these viruses. In particular, future surveillance studies should focus on wild waterfowl and the potential for the introduction of avian influenza viruses through migration and nomadic movements of these birds.

In this study we report that there is no evidence of avian influenza circulation in Papua New Guinean poultry populations. However, there are some limitations to this study. A cross-sectional analysis for avian influenza viruses may not be sufficiently sensitive when a low prevalence of virus is circulating. The short lifespan of poultry bred for meat and the low number of samples collected from each site may have contributed to the non-detection of avian influenza viruses and antibodies. Therefore, it is recommended that long-term sentinel surveillance should be established at sites where there is a risk of avian influenza introduction, such as sites close to border crossings and lakes used by waterfowl.

Although wild waterfowl migration routes are unlikely to be the source of exotic avian influenza introduction, the landborder with West Papua (Indonesia) and the poultry husbandry practices in Papua New Guinea mean that there is still a relatively high risk of introduction into the country. The introduction of HPAI viruses into Papua New Guinea could create a huge socioeconomic burden. Poultry provides the only source of protein consumption for many people in rural regions, and a large outbreak may have far-reaching health implications. Poor diagnostic capacity at a national level ${ }^{17}$ and limited outbreak response and mitigation capabilities may not be sufficient to contain an avian influenza outbreak.

\section{Conflict of interest}

None declared.

\section{Funding}

None.

\section{Acknowledgements}

This work was funded by the National Institute of Allergy and Infectious Diseases, the National Institutes of Health, under contract number HHSN266200700005C. Marinjho Jonduo was supported by a Partnership in Health Research Training Program, funded by Esso Highlands Papua New Guinea Limited.

\section{References:}

1. Influenza (Seasonal) Fact Sheet No. 211, 2009. Geneva, World Health Organization, 2009 (http://www.who.int/mediacentre/ factsheets/fs211/en/index.html, accessed 15 August 2013).

2. Webster RG et al. Evolution and ecology of influenza $A$ viruses. Microbiological Reviews, 1992, 56:152-179. pmid: 1579108

3. Tiensin T et al. Highly pathogenic avian influenza H5N1, Thailand, 2004. Emerging Infectious Diseases, 2005, 11:1664-1672. doi:10.3201/eid1111.050608 pmid:16318716

4. Alexander DJ. An overview of the epidemiology of avian influenza. Vaccine, 2007, 25:5637-5644. doi:10.1016/j. vaccine. 2006.10 .051 pmid: 17126960 
5. Gao R et al. Human infection with a novel avian-origin influenza $\mathrm{A}(\mathrm{H} 7 \mathrm{~N} 9)$ virus. The New England Journal of Medicine, 2013, 368:1888-1897. doi:10.1056/NEJMoa1304459 pmid:23577628

6. Bourke RM, Harwood T (Eds). Food and Agriculture in Papua New Guinea. ANU E Press, The Australian National University, Canberra, 2009.

7. Whitworth D et al (Eds). Wild Birds and Avian Influenza: an introduction to applied field research and disease sampling techniques. FAO Animal Production and Health Manual, No. 5. Rome, Food and Agriculture Organization of the United Nations (FAO), 2007 (ftp://ftp.fao.org/docrep/fao/010/a1521e/a1521e. pdf, accessed 10 August 2013).

8. Spackman E et al. Development of a real-time reverse transcriptase PCR assay for type A influenza virus and the avian H5 and H7 hemagglutinin subtypes. Journal of Clinical Microbiology, 2002, 40:3256-3260. doi:10.1128/JCM.40.9.3256-3260. 2002 pmid: 12202562

9. Zhou B et al. Single-reaction genomic amplification accelerates sequencing and vaccine production for classical and swine origin human influenza a viruses. Journal of Virology, 2009, 83:1030910313. doi:10.1128/JVI.01109-09 pmid:19605485

10. Hansbro PM et al. Surveillance and analysis of avian influenza viruses, Australia. Emerging Infectious Diseases, 2010, 16:18961904. doi:10.3201/eid1612.100776 pmid:21122219
11. Takano R et al. Phylogenetic characterization of H5N1 avian influenza viruses isolated in Indonesia from 2003-2007. Virology, 2009, 390:13-21. doi:10.1016/j.virol.2009.04.024 pmid: 19464724

12. Newcastle Disease - Papua New Guinea: (Sandaun) poultry. ProMed, 1 May 2013, archive no. 20130502.1685877 (http://www. promedmail.org/?archiveid =20130502.1685877, accessed 10 August 2013).

13. Horwood PF et al. Outbreak of chikungunya virus infection, Vanimo, Papua New Guinea. Emerging Infectious Diseases, 2013, 19:1535-1538. doi:10.3201/eid1909.130130 pmid:23965757

14. Olsen $B$ et al. Global patterns of influenza A virus in wild birds. Science, 2006, 312:384-388. doi:10.1126/science.1122438 pmid: 16627734

15. Roshier DA et al. Biogeographic models of gene flow in two waterfowl of the Australo-Papuan tropics. Ecology and Evolution, 2012, 2:2803-2814. doi:10.1002/ece3.393 pmid:23170215

16. Dingle $\mathrm{H}$. The Australo-Papuan bird migration system: another consequence of Wallace's Line. Emu, 2004, 104:95-108. doi:10.1071/MU03026

17. Greenhill A et al. Improved laboratory capacity is required to respond better to future cholera outbreaks in Papua New Guinea. Western Pacific Surveillance and Response Journal, 2012, 3:3032. doi:10.5365/wpsar.2011.2.4.016 pmid:23908909 